Research Paper

\title{
Bioinformatics based structural characterization of glucose dehydrogenase $(g d h)$ gene and growth promoting activity of Leclercia sp. QAU-66
}

\author{
Muhammad Naveed $^{1}$, Iftikhar Ahmed ${ }^{2}$, Nauman Khalid ${ }^{3}$, Abdul Samad Mumtaz ${ }^{1}$ \\ ${ }^{1}$ Plant Genomics Lab, Department of Plant Sciences, Quaid-i-Azam University, Islamabad, Pakistan. \\ ${ }^{2}$ National Institute for Genomics \& Advanced Biotechnology, National Agricultural Research Centre, \\ Islamabad, Pakistan. \\ ${ }^{3}$ Graduate School of Agricultural and Life Sciences, The University of Tokyo, Tokyo, Japan.
}

Submitted: June 9, 2013; Approved: September 9, 2013.

\begin{abstract}
Glucose dehydrogenase (GDH; EC 1.1. 5.2) is the member of quinoproteins group that use the redox cofactor pyrroloquinoline quinoine, calcium ions and glucose as substrate for its activity. In present study, Leclercia sp. QAU-66, isolated from rhizosphere of Vigna mungo, was characterized for phosphate solubilization and the role of GDH in plant growth promotion of Phaseolus vulgaris. The strain QAU-66 had ability to solubilize phosphorus and significantly $(\mathrm{p} \leq 0.05)$ promoted the shoot and root lengths of Phaseolus vulgaris. The structural determination of GDH protein was carried out using bioinformatics tools like Pfam, InterProScan, I-TASSER and COFACTOR. These tools predicted the structural based functional homology of pyrroloquinoline quinone domains in GDH. GDH of Leclercia sp. QAU-66 is one of the main factor that involved in plant growth promotion and provides a solid background for further research in plant growth promoting activities.
\end{abstract}

Key words: glucose dehydrogenase, pyrroloquinoline quinone, Leclercia sp., PGPR, bioinformatics.

\section{Introduction}

Escherichia adecarboxylata is a Gram negative bacterium that belonged to family Enterobacteriaceae, and was named by Richard (1984). Due to nucleic acid and protein electrophoretic differences, E. adecarboxylata was separated from the Enterobacter agglomerans complex (Izard et al., 1985) and reclassified as Leclercia adecarboxylata (Tamura et al., 1986). This bacterium is widely distributed in nature and has been reported from blood, food, water and other environmental sources (Tamura et al., 1986; Richard, 1989; Fliege et al., 1992). It is commonly characterized as oxidase-negative, facultativeanaerobic, mesophilic and having $\mathrm{G}+\mathrm{C}$ content of $52-54 \%$ (Richard, 1984; Tamura et al., 1986; Richard, 1989). However, in contrast to several other members of this family, enterobacterial common antigen was not detected in $L$. adecarboxylata (Brenner, 1992).
Organic matter decomposition in the rhizosphere is restrained by microbial activity (Lynch, 1990; Pinton et al., 2001). Plant and soil type, both influence the microbial diversity and community structure in the rhizosphere (Latour et al., 1996). Most of the essential plant nutrients obtained from soil include nitrogen, phosphorus (P), and potassium but $90-95 \%$ of total soil phosphate is considered as a plant unavailable P-source. Rhizobacteria colonize and proliferate in all ecological niches of plant roots at all stages of plant growth, and contain $g d h$ enzyme which play vital role in phosphate solubilization (Antoun and Kloepper, 2001).

Glucose dehydrogenase (GDH) is the member of quinoprotein group that use the redox cofactor pyrroloquinoline quinone (PQQ), $\mathrm{Ca}^{2+}$ ions and glucose as substrate for its activity (Duine et al., 1979). Membrane bound glucose dehydrogenase (m-GDHs) are $88 \mathrm{kDa}$ monomeric protein, present in various bacteria having similar primary structure but different in substrate specificities. The mGDH have hydrophobic $n$-terminal consists of five trans-

Send correspondence to M. Naveed. Plant Genomics Lab, Department of Plant Sciences, Quaid-i-Azam University, 44000 Islamabad, Pakistan. E-mail: naveed.quaidian@gmail.com. 
membrane segments, which anchor the protein in membrane, whereas $c$-terminal domain have a large conserved PQQ-binding sites with catalytic functions (Yamada et al., 1993).

GDH protein plays an important role in phosphate solubilization by acidification in the periplasmic space of bacteria through direct oxidation of glucose into gluconic acid and to 2-ketogluconic acid (Duine et al., 1979; Anthony and Ghosh, 1997). Gluconic and 2-keto gluconic acids are strongest naturally occurring acids secreted into the extracellular medium by bacteria (Duine, 1991). This pathway is important for the survival of enteric bacteria in aerobic, aquatic and low-phosphate environments (Fliege et al., 1992).

Bioinformatics tools play a vital role in revealing orphan pathways of many unknown valuable agricultural and pharmaceutical products of numerous prokaryotic organisms (McClerren et al., 2006; Sudek et al., 2006) by predicted studies of complete genomic sequences. Shen et al. (2012) used bioinformatics tools for homologue identification, multiple sequence alignment, phylogenetic tree construction and analysis, protein structure prediction, and functional site identification in PQQ and GDH protein.

The main aim of present study was to delineate the interaction of Leclercia sp. QAU-66 with plant growth promotion activity and its capacity to solubilize the phosphate in rhizosphere of plant by highlighting the important role of glucose dehydrogenase $(g d h)$ gene. In addition, the taxonomic study of Leclercia sp. QAU-66 was carried out together with structural analysis of $g d h$ gene by using different bioinformatics tools.

\section{Material and Methods}

\section{Bacterial isolation and phenotypic characterization}

Bacterial strains were isolated from rhizosphere of Vigna mungo of Islamabad region in Pakistan by washing-off soil particles adhering to root system and shaking the roots for about $5 \mathrm{~min}$ in Milli-Q water. The soil samples were homogenized in Milli-Q water containing 0.89\% $\mathrm{NaCl}(\mathrm{w} / \mathrm{v})$ and diluted according to serial dilution method by using phosphate buffered saline (PBS, $1 \mathrm{x}$ ). Aliquots of each dilution were spread on Luria Bertani (LB) medium (pH 7.5) and incubated at $30^{\circ} \mathrm{C}$ for $18-24 \mathrm{~h}$. Selected colonies of bacteria were sub-cultured repeatedly on LB media to obtained pure cultures. These cultures were preserved in $20 \%$ glycerol at $-80{ }^{\circ} \mathrm{C}$ for further experimentation. Phenotypic characterization of rhizobacterial isolates were carried out through morphological and microscopic observations.

\section{Biochemical and physiological characterization}

The strain QAU-66 was biochemically tested for Indole acetic acid (IAA) production (Joseph et al., 2007), and catalase (MacFadden, 1976), whereas in physiological tests the nitrogenase activity was observed as change in colour (translucent to blue) on the NFB medium (Dobereiner and Day, 1976). The ability of phosphate solubilization was determined by using Pikovskaya medium amended with bromo phenol blue. The phosphate solubilization efficiency of the strains was determined by ratio of diameter of the halo zone and the bacterial colony (Edi-Premoto et al., 1996).

\section{Amplification of 16S rRNA gene and glucose dehydrogenase $(g d h)$ gene by PCR}

Genomic DNA of bacterium was extracted by the CTAB method (Sambrook et al., 1989). The strains were identified by using 16S rRNA gene sequence and the phylogenetic analysis. To amplify the $16 \mathrm{~S}$ rRNA gene, universal primers P1 (5'-AGA GTT TGA TCC TGG TCA GAA CGA ACG CT-3') and P6 (5'-TAC GGC TAC CTT GTT ACG ACT TCA CCC C-3') were used corresponding to E.coli positions 8-37 for forward primer and 1479- 1506 for reverse primer, respectively (Tan et al., 1997). The PCR cycling parameters consisted of an initial denaturation at $94{ }^{\circ} \mathrm{C}$ for $2 \mathrm{~min}$, followed by 30 cycles of denaturation at $94^{\circ} \mathrm{C}$ for $1 \mathrm{~min}$, annealing at $54^{\circ} \mathrm{C}$ for $1 \mathrm{~min}$ and extension at $72{ }^{\circ} \mathrm{C}$ for $1.5 \mathrm{~min}$ and a final extension for $5 \mathrm{~min}$ at $72^{\circ} \mathrm{C}$.

To amplify the region of $1.3 \mathrm{~kb}$ encoding membrane glucose dehydrogenase $(g d h)$ gene, a primer set $g d h \mathrm{Fp}$ (5'-CCC GAA TTC GGC GTG ATC CGT GGT T-3') and $g d h$ Rp (5'-ATG CGT CGA CTA GTC GCC CAT CTT-3') was used. The reaction mixture $(25 \mu \mathrm{L})$ was prepared and amplification reaction was performed with initial temperature of $94{ }^{\circ} \mathrm{C}$ for 2 min followed by 35 cycles consisting of $94{ }^{\circ} \mathrm{C}$ for $1 \mathrm{~min}$; primer annealing at $54{ }^{\circ} \mathrm{C}$ for $1 \mathrm{~min}$ and primer extension at $72{ }^{\circ} \mathrm{C}$ for $1 \mathrm{~min}$ and final extension at $72{ }^{\circ} \mathrm{C}$ for $10 \mathrm{~min}$ in a thermal cycler (Biometra, Germany).

\section{Sequencing and phylogenetic analysis based on 16S rRNA gene and gdh gene}

Amplified PCR products of the 16S rRNA gene and $g d h$ gene were sequenced using commercial service of MACROGEN (http://dna.macrogen.com/eng/ Seoul, Korea). The strain was identified using the sequence of $16 \mathrm{~S}$ rRNA gene on Ez-Taxon Server (http://eztaxon-e.ezbiocloud.net) and BLAST search on DDBJ / NCBI servers. For phylogenetic analysis of strain QAU-66, the closely related validly published 16S rRNA sequences of type strains were retrieved from EzTaxon Server Database, whereas the available sequence of $g d h$ gene of the closely related species were retrieved from NCBI DNA database. The phylogenetic analyses were performed as described previously (Roohi et al., 2012) using three algorithms: neighbor joining (NJ), maximum parsimony (MP) and maximum likelihood (MLH). Phylogenetic and molecular evolutionary analyses were carried out using MEGA version 5.10 program (Tamura et al., 2011). The stability of the relationship was assessed by bootstrap anal- 
ysis by performing 1000 resampling for the tree topology of the neighbour-joining method.

\section{Bioinformatics based structural analyses of GDH protein}

Nucleotide

BLAST

(http://www.ncbi.nlm.nih.gov/blast.cgi).nBLAST) and Protein BLAST of UniPort were used to find the sequences similarity with previously reported sequences in NCBI databases and then ClustalW2 tool was used for multiple sequence alignment (MSA) of DNA and proteins sequences. These tools were used to get information regarding the function and structure of newly sequenced genes by exploring evolutionary relationships and predicting new members of gene families (Durbin et al., 1998). ExPASy translated program (http://web.expasy.org/translate/) was used to translate the nucleotide sequences into amino acid sequences according to standard genetic code for 3D structural analysis.

\section{Determination of Physico-chemical Properties of GDH protein}

The physico-chemical properties of GDH amino acid sequence was calculated by different bioinformatics tools. Pepstats (Harrison, 2000) was used to calculate statistics of proteins i.e. average residue weight, molecular weight, isoelectric point and charge. ProtParam (Gasteiger et al., 2005) was used to compute amino acid composition, atomic composition and instability index. Whereas, Pepwindow (Kyte and Doolittle, 1982) was used to draws a hydropathy plot which is valuable in determining the distribution of polar and apolar residues of protein sequence.

\section{Structural and functional Analysis of GDH Protein}

PSIPred was used to predict secondary structure ( $\alpha$-helix, $\beta$-strand or coil) of GDH protein. I-TASSER tool was used to generate the high quality 3D model of GDH (Zhang, 2008) based on multiple-threading alignments of its amino acid sequences in pdb file. The biological and functional insights of predicted model were done by matching with protein function database. The structure based functions like gene ontology terms, ligand binding sites and enzyme classification of GDH proteins were determined from COFACTOR program (Roy et al., 2012) by using previously generated $\mathrm{pdb}$ file of $3 \mathrm{D}$ model. Functional sites or domains of GDH protein, its occurrence in the sequence, domains length and protein family of GDH proteins were determined with the help of InterProScan tool (Quevillon et al., 2005), whereas GPS 2.1 DOG programme (Ren et al., 2009) was used for the construction of GDH protein domains, functional peptide and cleavage site of GDH proteins.

\section{Plant growth promotion (PGPR) activity of Leclercia sp. QAU-66}

Phaseolus vulgaris seeds were used as plant materials in pots under control conditions. A complete randomized design (CRD) was employed as the experimental design with five replications. Seeds were surface sterilized with chlorine tablets for $2 \mathrm{~min}$, and washed with sterilized distilled water at least 3 times to remove traces of chlorine. After air drying, the seeds were sown into pertri dishes having soaked filter papers for germination at $28{ }^{\circ} \mathrm{C}$. For experiment, strain QAU-66 was grown overnight on King B medium. The bacterial cells were harvested by centrifuge and suspended in $100 \mathrm{~mL}$ saline solution. This culture $(1 \mathrm{~mL}$ of saline solution containing bacterial cells $10^{6} \mathrm{cfu}$ ) was used to inoculate the soil contained in pots. Ten seeds were sown in each pot and un-inoculated pots were used as control. Pots were irrigated with sterile tap water when needed up to the harvest of plants (15 days after inoculation).

Data was recorded on growth parameters (viz. plant root, shoot length and weight, leave area index and total number of leafs) on five plants which were randomly uprooted from each plot after 15 days of growth.

\section{Results}

\section{Bacterial isolation and phenotypic characterization}

The bacterial strain QAU-66 was found to be Gram negative and cocci. The strain was positive for IAA and catalase production, whereas negative for nitrogenase activity. After 4 days, a decrease in $\mathrm{pH}$ was observed for strain QAU-66 in Pikovskaya broth from an initial value of 7 to $4 \mathrm{pH}$. The role of strain QAU-66 in phosphate solubilization was also confirmed on Pikoviskay medium. Clear zones (solubility index, SI $=3.3$ ) of phosphate solubilization (Tricalcium phosphate) was measured after 1 week of incubation at $28^{\circ} \mathrm{C}$ (Figure 1a).

\section{S rRNA gene, gdh gene identification and phylogenetic analysis}

The strain QAU-66 was identified by comparison of 16S rRNA gene sequences (1500 base pairs) on EzTaxon Server. The strain QAU-66 belong to the genus Leclercia, based on high sequence similarity (99.39\%) with Leclercia adecarboxylata (AB273740). However, the neighbourjoining phylogenetic tree (Figure 2a) incurred from $16 \mathrm{~S}$ rRNA gene sequence showed that strain QAU-66 has close neighbouring with Enterobacter hormaechei (AFHR01000079) and two more species of Enterobacter, but it has low bootstrap value with this cluster. Similar tree topology was observed when phylogenetic analysis was performed by using Maximum-parsimony (MP) and Maximum-likelihood algorithms. BLAST result showed that gdh gene sequence (1271 base pairs) of Leclercia sp. QAU-66 is most closely related to the genus Enterobacter with $99 \%$ sequence similarity. The phylogenetic analysis 


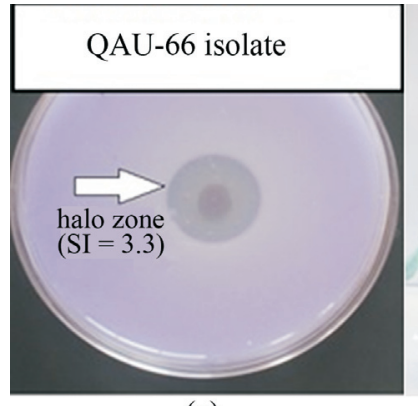

(a)

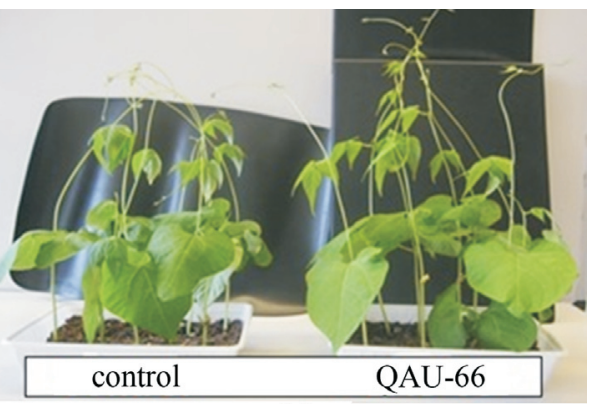

(b)

Figure 1 - (a) Phosphate solubilization of strain QAU-66, SI (solubility index). (b) Plant growth promoting activity of strain QAU-66 on Phaseolus vulgaris.

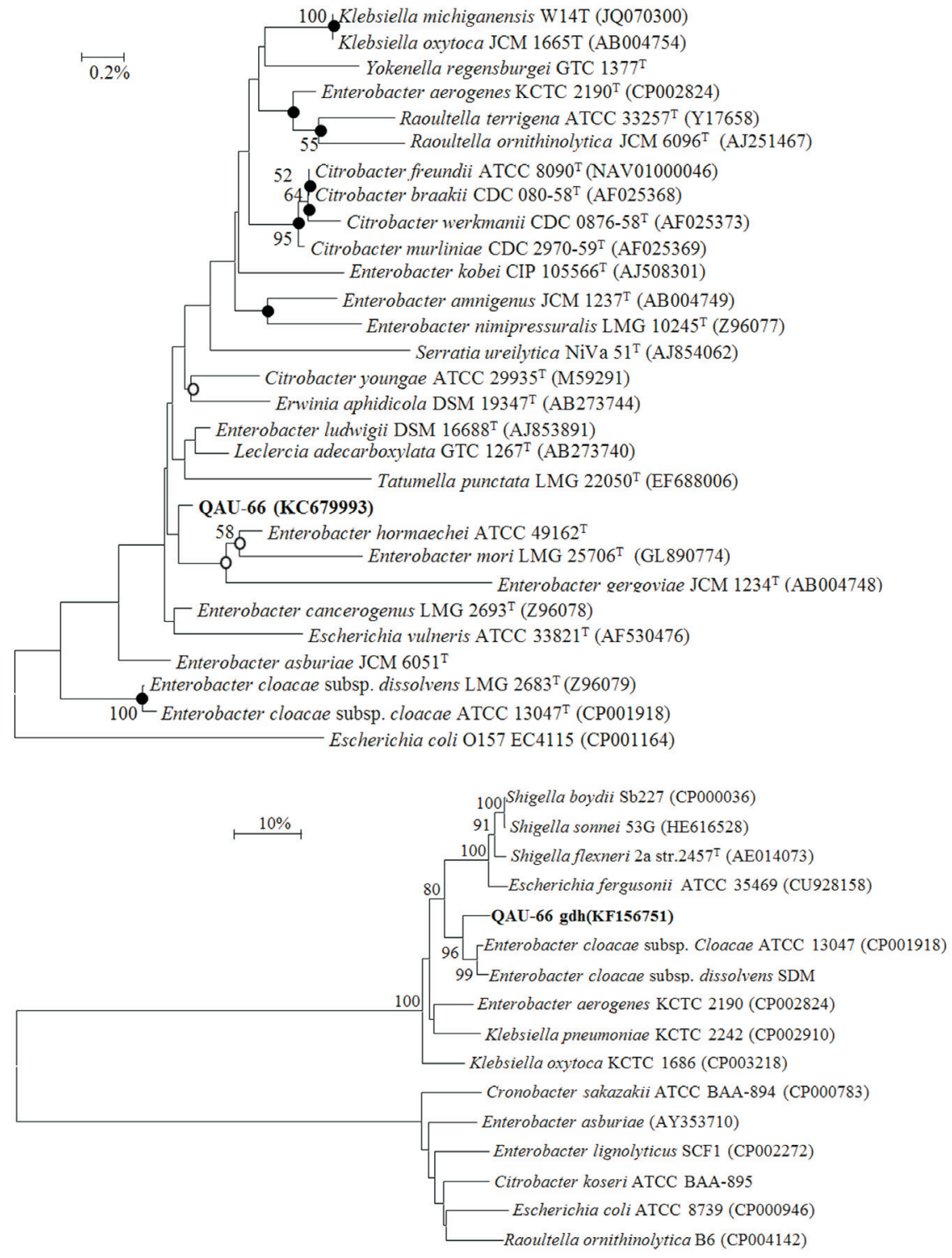

Figure 2 - (a) Neighbour-joining phylogenetic tree showing the inter-relationship of strain QAU-66 with the closely related validly published species inferred from sequences of 16S rRNA gene. Escherichia coli (CP001164) was used as an out group. Bootstrap values (only more than 50\%) are expressed as a percentage of 1000 replications, are given at the branching point. Nodes indicated by solid circles were recovered by three algorithms: NJ; MP and MLH methods, whereas nodes with empty circles were recovered at least by two algorithms. The Bar show $0.2 \%$ sequence divergence. The accession number of each strain is shown in parenthesis. (b) Neighbour-joining phylogenetic tree showing the inter-relationship of strain QAU-66 with the closely related species inferred from sequences of glucose dehydrogenase gene. Bootstrap values (only more than 50\%) are expressed as a percentage of 1000 replications, are given at the branching point. The Bar show 10\% sequence divergence. The accession number of each strain is shown in parenthesis. 
(Figure $2 \mathrm{~b}$ ) based on $g d h$ gene sequence (1271 base pairs) showed that QAU-66 GDH clustered with previously characterized GDH of Enterobacter cloacae. The assembled sequence of $16 \mathrm{~S}$ rRNA gene and $g d h$ gene were submitted to NCBI under the Accession numbers KC679993 and KF156751 respectively.

\section{PGPR activity of Leclercia sp. QAU-66}

Inoculated seeds with strain QAU-66 showed significant difference $(p<0.05)$ in shoot length, root weight and total numbers of leaves in comparison with control (Table 1). The inoculated plants has an average root weight of $1.1 \pm 0.16 \mathrm{~g}$ in comparison to control $(0.7 \pm 0.13 \mathrm{~g})$. An increase of $10 \%$ in shoot and root length of Phaseolus vulgaris was observed with inoculation of strain QAU-66. Similarly, number of leaves also increased in inoculated plants in comparison to control (Figure 1b). The increase in growth corresponds towards the PGPR activity of strain QAU-66.

\section{Bioinformatics analysis}

\section{Identification and Physico-chemical Properties of GDH protein}

The obtained nucleotide sequence was subjected to ExPASy portal tools for presence of potential open reading frames (ORF). The analysis revealed a presence of large ORF potentially coding for a 377 amino acid, protein. UniPort (BlastP) identified the homology of amino acids with sequences available in database which showed $99 \%$ identity with glucose dehydrogenase of Enterobacter cloacae subsp. cloacae ENHKU01 (J7G7S7_ENTCL) and confirmed that the studied sequence belongs to GDH. Leclercia sp. QAU-66 glucose dehydrogenase (GDH) has molecular weight of $40741.6 \mathrm{~g}$, with average residual weight of $108.0 \mathrm{~g}$. The high molecular weight corresponds toward the net charge of 4.0 with isoelectric point of 8.5 which was studied from Emboss Pepstats tool. ProtParam tool showed that Leclercia sp. QAU-66 composed of 377 amino acids with 29 (Asp + Glu) negative charge residues and 31 (Arg + Lys) positive charge residues. Higher contents of proline, glycine and alanine were also observed by ProtParam tool. The atomic composition $\left(\mathrm{C}_{1840} \mathrm{H}_{2829} \mathrm{~N}_{483} \mathrm{O}_{526} \mathrm{~S}_{19}\right)$ of QAU-66 GDH protein showed that it has 5697 atoms.

Hydrophobicity plot was generated by Pepwindow to characterize structure based distribution of polar (hydro- philic) and apolar (hydrophobic) residues along a GDH. Hydropathicity grand average score (GRAVY) of -0.209 indicates that Leclercia sp. QAU-66 GDH protein has more hydrophilic residues.

\section{Structural analysis of GDH Protein}

PSIPRED server was used to determine the secondary structure of GDH. The results showed that GDH mainly composed up of $\beta$-strands, $\alpha$-helix and coils (Figure 3a). The presence of excess numbers of $\beta$ - strands $(37 \%)$ in Leclercia sp. QAU-66 corresponds towards its $\beta$ propeller nature which is the structural property of GDH proteins.

Structure based function annotations of GDH protein was determined by I-TASSER, COFACTOR, Coach and BioLip program. From the obtained amino acid sequence, 3D structure was constructed by using I-TASSER (Figure 4a) and the predicted structure showed homology to the Quinohemoprotein alcohol dehydrogenase (1yiqA1) template with TM-score of 0.800 (it is the structural alignment between query structure and known structure in pdb library). The functional insights like classification of proteins, specific ligand binding sites and gene ontology terms were then inferred by comparison with protein structural models with known functions. Afterwards, COFACTOR tool gave top five enzyme homologue of GDH protein with C-score of 0.398 and was nearly homologue to 1yiqA1 (C-score is the confidence score for enzyme classification (EC) number predication). COFACTOR also showed that the predicted binding site of GDH protein having PQQ and $\mathrm{Ca}$ ligands with $\mathrm{C}$-score of 0.12 (Figure $4 \mathrm{~b}$ ).

\section{Functional domain prediction of GDH proteins}

Functional sites of GDH protein was determined by InterProScan and COFACTOR (structure based function prediction). InterProScan was showed that it has three PQQ repetitive domains sites (in between 18-50, 243-277 and 303-340 residues) and revealed good functional homology with quinoprotein alcohol dehydrogenase (148-375 residues). The PQQ domains were further confirmed with Pfam program which showed the presence of PQQ repeats in GDH protein of Leclercia sp. QAU-66.

Gene ontology predicts the biological, molecular and cellular functions of GDH protein which showed that it involve in oxidation-reduction process (GO: 0055114), oxidoreductase activity, acting on $\mathrm{CH}-\mathrm{OH}$ group of donors (GO: 0016614), quinone binding (GO: 0048038), calcium ion binding (GO: 0005509) and its presence in outer mem-

Table 1 - Effect of Leclercia sp. QAU-66 on growth of Phaseolus vulgaris.

\begin{tabular}{lcccccc}
\hline Treatment & Shoot length & Root length & Shoot weight & Root weight & Leaf area & Total leaf \\
\hline Control & $51.4 \pm 1.29^{\mathrm{b}}$ & $14.3 \pm 2.21^{\mathrm{a}}$ & $3.7 \pm 5.20^{\mathrm{a}}$ & $0.7 \pm 0.13^{\mathrm{b}}$ & $79.4 \pm 13.00^{\mathrm{a}}$ & $5.0 \pm 0.00^{\mathrm{b}}$ \\
Leclercia sp. (QAU-66) & $58.6 \pm 2.32^{\mathrm{a}}$ & $17.3 \pm 3.64^{\mathrm{b}}$ & $4.1 \pm 0.25^{\mathrm{a}}$ & $1.1 \pm 0.16^{\mathrm{a}}$ & $82.6 \pm 14.66^{\mathrm{a}}$ & $7.4 \pm 1.34^{\mathrm{a}}$ \\
\hline
\end{tabular}

Data are average values of five replicates \pm SD. Mean with different letters in the same column differ significantly at $\mathrm{p} \leq 0.05$ (Fisher's protected LSD). 
(a)

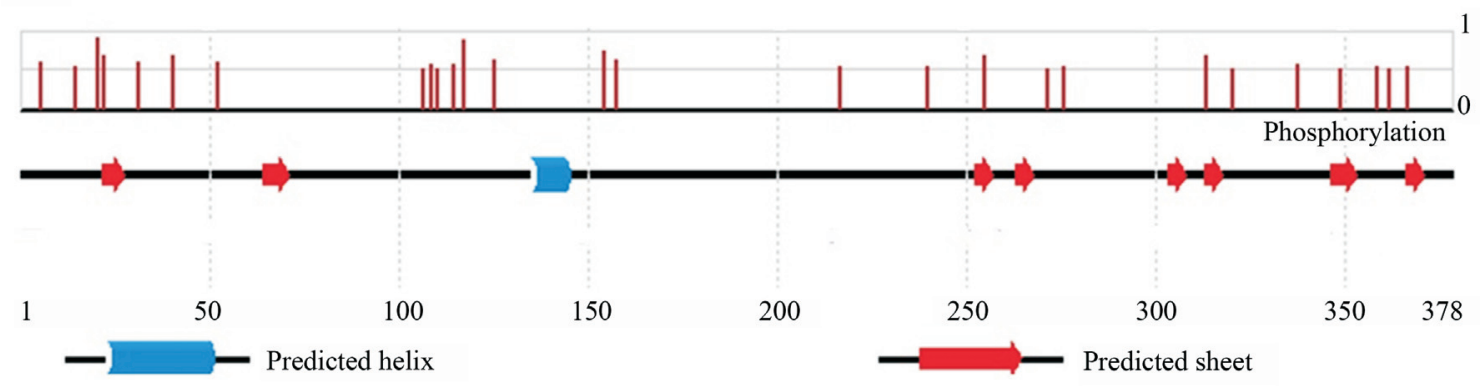

(b)
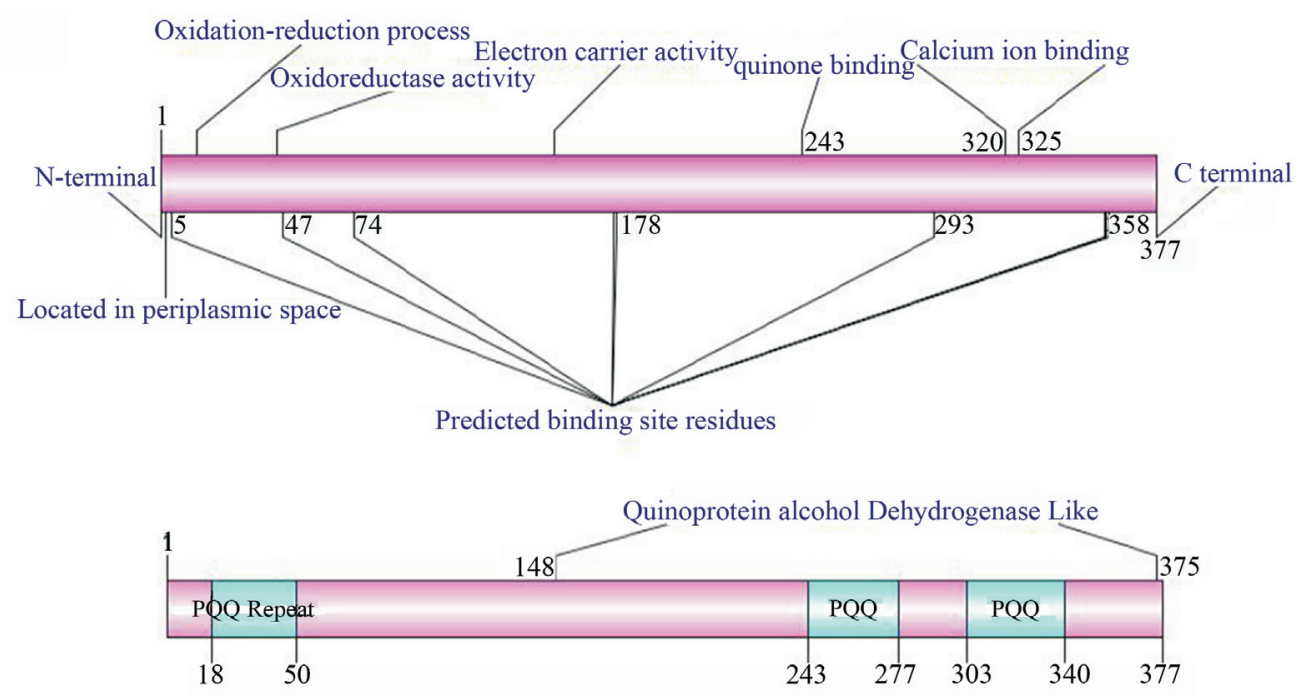

Leclercia adecarboxylata QAU66 Glucose Dehydrogenase Model

Figure 3 - (a) PSIPRED schematic presentation of secondary structure of QAU-66 GDH and position dependent features of Phosphorylation. The line height of the Phosphorylation features reflects the confidence of the residue prediction. The blue color represents the $\alpha$-helix and red colour represents the $\beta$-strands. (b) Functional domains of QAU-66 GDH (A \& B) predicted by INTERPROSCAN and COFACTOR respectively, and then drawn by DOG 2.0 (illustrator of protein domain structures).

brane-bounded periplasmic space (GO: 0030288) which depict homology with functional features of glucose dehydrogenase. Based upon all identified functions, the overall structural based functional model (Figure 3b) of Leclercia sp. QAU-66 was generated from GPS 2.1 DOG programme.

\section{Discussion}

Microorganisms secretes organic acid in rhizosphere that results in phosphate solubilization from insoluble complexes and make it available to the plants (Richardson et al., 2009). This solubilization takes place by direct oxidation of glucose into gluconic acid by the membrane bound glucose dehydrogenase (Gyaneshwar et al., 1999). Strain QAU-66 also solubilized the inorganic phosphate to organic, which was confirmed by phosphate solubilization efficiency and clear halo zone on Pikovskaya's medium (Figure 1a).

Members of Enterobacteriaceae such as E. asburiae play a significant role in phosphate solubilization and this process is due to $g d h$ gene which is conserved in this bacterial family. In present study, a $1.2 \mathrm{~kb}$ partial sequence of Leclercia sp. QAU-66 gdh gene was amplified with designed primers from conserved $g d h$ gene of Enterobacteriaceae and the amplified product was sequenced. The obtained nucleotide and protein sequence homology of $99 \%$ with glucose dehydrogenase of $E$. cloacae subsp. cloacae (ENHKU01), confirming the isolation of $g d h$ gene from Enterobacteriaceae. The $g d h$ gene in Enterobacteriaceae members plays a significant role in sugar metabolism (conversion of glucose into gluconic acid), but there are other oxidative pathways of this conversion, when growth become restricted due to energy shortage (Tripura et al., 2007).

In past studies, most of the members of Enterobacteriaceae were characterized as human pathogens (Brenner et al., 1986) and safety concerns are there for human health. However, in present study, the Leclercia sp. QAU-66 was isolated from rhizosphere of Vigna mungo and studied for their various plant growth promoting activi- 
(a)

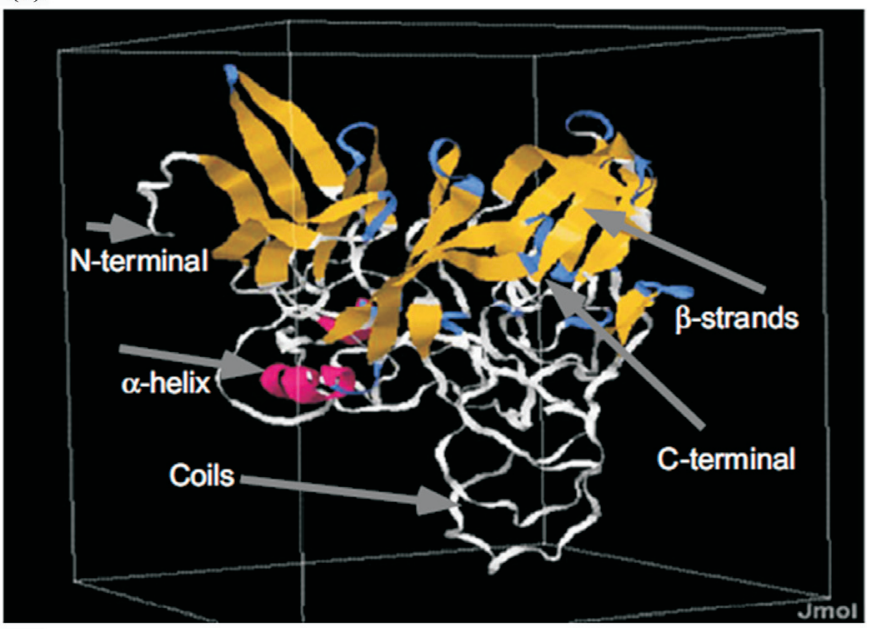

(b)

QAU-6 GDH I-TASSER model

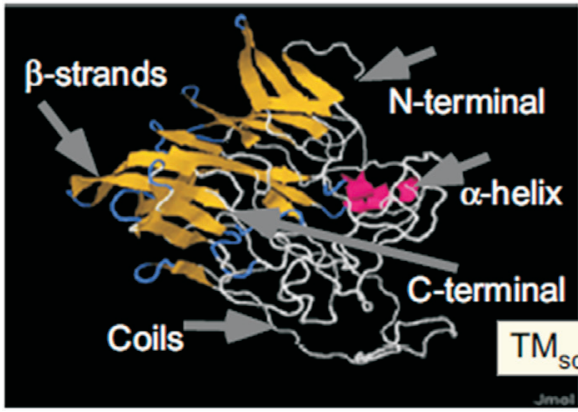

Deduced functional homologue (1 yiqA1)

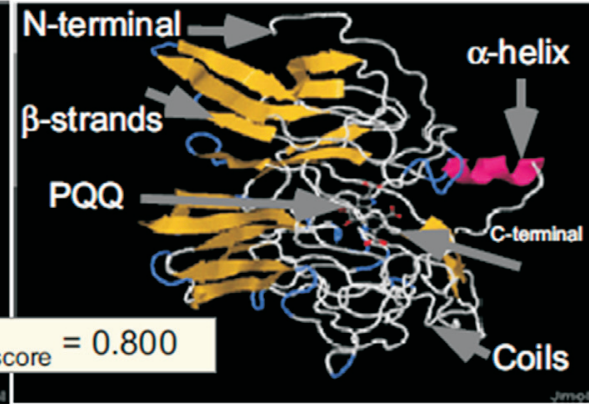

Figure 4 - (a) Predicted 3D model of Leclercia sp. QAU-66 GDH obtained from I-TASSER and visualized on Jmol. (b) Protein function annotations based on the sequence-to-structure-to-function paradigm for GDH. The right panel is the function homology identified by global and local matches of I-TASSER models showing binding sites of PQQ cofactor and homology with quninhemoprotein alcohol dehydrogenase (1yiqA1) template with TM-score of 0.800 (TM score is a measure of global structural similarity between query and template protein).

ties. Members of Enterobacteriaceae play important role in plant growth promotion (Zakria et al., 2008; Ahemad and Khan, 2010; Rogers et al., 2012; Hayat et al., 2010), but no such reports are there for the genus Leclercia. The plant growth promoting activity of Leclercia sp. QAU-66 was firstly reported in this study by phosphate solubilization and plant growth promoting activities.

The growth promoting effects of Leclercia sp. QAU66 was observed in Phaseolus vulgaris. The results showed significant difference $(p<0.05)$ in shoot length, root weight and total numbers of leaves in comparison with control (Table 1, Figure 1b). The shoot and root lengths of Phaseolus vulgaris were increased by $10 \%$ with the inoculation of Leclercia sp. QAU-66, which depicted its plant growth promotion activity. The above results are in line with Morales-García et al. (2011), who reported that maize plants inoculated with Enterobacter sp. UAPS03001 showed statistically significant greater biomass than the controls under environmental chamber conditions. In another study Zakria et al. (2008) showed that under glass house conditions, Brassica oleracea inoculated with Enterobacter sp. strain 35 had a significantly greater fresh weight than uninoculated plants.

Bioinformatics play a leading role in structure based functional determination, gene expression, ligands binding sites and phylogenetic analysis of proteins (Shen et al., 2012). In this study, various bioinformatics tools were used to characterize the glucose dehydrogenase of Leclercia sp. QAU-66. The physicochemical characteristics were determined by Emboss Pepstats and ProtParam tools that gives good results in basic characterization (molecular weight, amino acid composition and contents etc.). The obtained GRAVY value (-2.09) in Leclercia sp. QAU-66 GDH indicates that most likely it has more hydrophilic nature and exposed to the surface of the protein and hence potentially antigenic (Kyte and Doolittle, 1982) which depict its catalytically activity.

The glucose dehydrogenase of Leclercia sp. QAU-66 contain 377 amino acid putative protein have $c$-terminal PQQ domain and $n$-terminal domain having a transmembrane $\alpha$-helix with $\beta$-strands which anchor the protein in cell membrane. The similar concept was earlier described by Yamada et al. (1993) that GDHs anchorage in mem- 
brane was due to five transmembrane segment $n$-terminal hydrophobic domain whereas, the catalytic activity was because of conserved pyrroloquinoline quinone (PQQ) on $c$-terminal. Chen et al. (2002) determined the conserved nature of PQQ domain in ADH protein of Pseudomonas putida $\mathrm{HK} 5$ and has catalytic activity that converts glucose to gluconic acid. Leclercia sp. QAU-66 GDH having similar three conserved PQQ repetitive domains which were confirmed by Interproscan tool.

The overall structure and position of GDH protein domains were confirmed by bioinformatics tools like InterProScan and Pfam programs. Pfam is a comprehensive collection of protein domains and families (Bateman et al., 2004) and in this study it was used to differentiate homologues sharing of QAU-66 GDH domain with same function from those that have divergent function in different Pfam families.

The secondary structure obtained from PSSpred showed 37\% $\beta$-strands present in QAU-66 GDH which depicts its resemblance with 8 propellers $\beta$-strands like in structure of alcohol dehydrogenase (Chen et al., 2002). Leclercia sp. QAU-66 GDH showed structural homology with Quinohemoprotein alcohol dehydrogenase (1yiqA1) template with TM-score of 0.800 which is predicted by I-TRASSER and COFACTOR tools, which further confirmed by the same gene ontology (biological, molecular and cellular functions) of QAU-66 GDH with ADH protein of Pseudomonas putida (Chen et al., 2002).

\section{Conclusions}

In present study, Leclercia sp. QAU-66 was firstly reported from rhizosphere of Vigna mungo. This study predicted its role in phosphate solubilization and explored the structure of glucose dehydrogenase of Leclercia sp. QAU66. Bioinformatics tools predict GDH homology with previously reported glucose dehydrogenases like gene ontology and structural based functional domains that were not previously reported for Leclercia sp. Furthermore, its significance in plant growth promotion was confirmed on Phaseolus vulgaris. The study concluded that glucose dehydrogenase of Leclercia sp. QAU-66 is one of the main factor involved in plant growth promotion by direct oxidation of glucose into gluconic acid and its presence in plant rhizosphere decrease the safety concerns and provides a solid background for further research in plant growth promoting activities.

\section{Acknowledgments}

The first author gratefully acknowledges a scholarship from Higher Education Commission (HEC) Pakistan. The study was funded by HEC as a part of strengthening the Universities in Pakistan by enhancing the PhD Studies.

\section{References}

Ahemad M, Khan M (2010) Plant Growth Promoting Activities of Phosphate Solubilizing Enterobacter as- buriae as Influenced by Fungicides. EurAsian J BioSci 4:88-95.

Anthony C, Ghosh M (1997) The structure and function of PQQcontaining quino proteins. Curr Sci 72:716-727.

Antoun, H, Kloepper JW (2001) Plant Growth promoting rhizobacteria. In Brenner S., Miller J.F. (eds.). Encyclopedia of Genetics. Academic Press. 1477-1480.

Bateman A, Coin L, Durbin R, Finn RD, Hollich V, GriffithsJones S, Khanna A, Marshall M, Moxon S, Sonnhammer ELL, Studholme DJ, Yeats C, Eddy SR (2004) The Pfam protein families database. Nucleic Acids Res 32:D138D141.

Brenner D (1992) Additional genera of Enterobacteriaceae. The prokaryotes. A handbook on the biology of bacteria: Ecophysiology, isolation, identification, applications. Springer, New York.

Brenner DJ, McWhorter AC, Kai A, Steigerwalt AG, Farmer JJ (1986) Enterobacter asburiae sp. nov., a new species found in clinical specimens, and reassignment of Erwinia dissolvens and Erwinia nimipressuralis to the genus Enterobacter as Enterobacter dissolvens comb. nov. and Enterobacter nimipressuralis comb. nov. J Clin Microbiol 23:1114-1120.

Chen ZW, Matsushita K, Yamashita T, Fujii TA, Toyama H, Adachi O, Bellamy HD, Mathews FS (2002) Structure at $1.9 \AA$ Resolution of a Quinohemoprotein Alcohol Dehydrogenase from Pseudomonas putida HK5. Structure 10:837849.

Dobereiner J, Day JM (1976) Associative symbiosis and freeliving systems. In: Newton WE, Nyman CJ (eds) 1st International symposium on Nitrogen fixation., Washington state University. Pullman Press, pp 518-538.

Duine J, Frank J, van Zeeland J (1979) Glucose dehydrogenase from Acinetobacter calcoaceticus: A 'quinoprotein'. FEBS Lett 15:443-446.

Duine JA (1991) Quinoproteins: Enzymes containing the quinonoid cofactor pyrroloquinoline quinone, topaquinone or tryptophan-tryptophan quinone. Eur J Biochem 200:271284.

Durbin R, Eddy SR, Krogh A, Mitchison G (1998) Biological sequence analysis: Probabilistic models of proteins and nucleic acids. Cambridge University Press, Cambridge.

Edi-Premoto M, Moawad AM, Vlek PLG (1996) Effect of phosphate solubilizing Pseudomonas putida on the growth of maize and its survival in the rhizosphere. Indonesian J Crop Sci 11:13-23.

Fliege R, Tong S, Shibata A, Nickerson KW, Conway T (1992) The Entner-Doudoroff pathway in Escherichia coli is induced for oxidative glucose metabolism via pyrroloquinoline quinone-dependent glucose dehydrogenase. Appl Environ Microbiol 58:3826-3829.

Gasteiger E, Hoogland C, Gattiker A, Duvaud S, Wilkins M, Appel R, Bairoch A (2005) Protein identification and analysis tools on the ExPASy server. The Proteomics Protocols Handbook. Humana Press, Totowa.

Gyaneshwar P, Parekh LJ, Archana G, Poole PS, Collins MD, Hutson RA, Kumar GN (1999) Involvement of a phosphate starvation inducible glucose dehydrogenase in soil phosphate solubilization by Enterobacter asburiae. FEMS Microbiol Lett 171:223-229. 
Harrison R (2000) Expression of soluble heterologous proteins via fusion with NusA protein. inNovations 11:4-7.

Hayat R, Ali S, Amara U, Khalid R, Ahmed I (2010) Soil beneficial bacteria and their role in plant growth promotion: A review. Ann Microbiol 60:579-598.

Izard D, Mergaert J, Gavini F, Beji A, Kersters K, De Ley J, Leclerc H (1985) Separation of Escherichia adecarboxylata from the «Erwinia herbicola-enterobacter agglomerans complex and from the other Enterobacteriaceae by nucleic acid and protein electrophoretic techniques. Annales de l'Institut Pasteur / Microbiologie 136:151-168.

Joseph B, Patra RR, Lawrence R (2007) Characterization of plant growth promoting rhizobacteria associated with chickpea. International Journal of Plant Production 1:141-151.

Kyte J, Doolittle RF (1982) A simple method for displaying the hydropathic character of a protein. J Mol Biol 157 :105-132.

Latour X, Corberand T, Laguerre G, Allard F, Lemanceau P (1996) The composition of fluorescent pseudomonad populations associated with roots is influenced by plant and soil type. Appl Environ Microbiol 62:2449-2456.

Lynch, JM (1990) The Rhizosphere. John Wiley and Sons, New York.

MacFadden JF (1976) Biochemical Tests for Identification of Medical Bacteria. Williams and Wilkins, Baltimore.

McClerren AL, Cooper LE, Quan C, Thomas PM, Kelleher NL, van der Donk WA (2006) Discovery and in vitro biosynthesis of haloduracin, a two-component lantibiotic. Proc Nat Acad Sci 103:17243-17248.

Morales-García Y, Juárez-Hernández D, Aragón-Hernández C, Mascarua-Esparza M, Bustillos-Cristales M, Fuentes-Ramírez L, Martinez-Contreras R, Munoz-Rojas J (2011) Growth response of maize plantlets inoculated with Enterobacter spp., as a model for alternative agriculture. Rev Argent Microbiol 43:287-293.

Pinton R, Varanini Z, Nannipieri P (2001) The Rhizosphere. Biochemistry and Organic Substances at the Soil-Plant Interface. Marcel Dekker, New York.

Quevillon E, Silventoinen V, Pillai S, Harte N, Mulder N, Apweiler R, Lopez R (2005) InterProScan: Protein domains identifier. Nucleic Acids Res 33:W116.

Ren J, Wen L, Gao X, Jin C, Xue Y, Yao X (2009) DOG 1.0: Illustrator of protein domain structures. Cell Res 19:271-273.

Richard C (1984) Nouvelles especes d'enterobacteriaceae (19791983). Bull Inst Pasteur 82:255-277.

Richard C (1989) Nouvelles Enterobacteriaceae rencontrees en bacteriologie medicale: Moellerella wisconsensis, Koserella trabulsii, Leclercia adecarboxylata, Escherichia fergusonii, Enterobacter asburiae, Rahnella aquatilis. Ann Biol Clin 47:231-236.

Richardson A, Barea J-M, McNeill A, Prigent-Combaret C (2009) Acquisition of phosphorus and nitrogen in the rhizosphere and plant growth promotion by microorganisms. Plant Soil 321:305-339.

Rogers A, McDonald K, Muehlbauer M, Hoffman A, Koenig K, Newman L, Taghavi S, Lelie D (2012) Inoculation of hybrid poplar with the endophytic bacterium Enterobacter sp. 638 increases biomass but does not impact leaf level physiology. Global Change Biol Bioenergy 4:364-370.

Roohi A, Ahmed I, Iqbal M, Jamil M (2012) Preliminary isolation and characterization of halotolerant and halophilic bacteria from salt mines of karak, pakistan. Pak J Bot 44:365-370.

Roy A, Yang J, Zhang Y (2012) COFACTOR: An accurate comparative algorithm for structure-based protein function annotation. Nucleic Acids Res 40(W1):W471-W477.

Shen Y-Q, Bonnot F, Imsand EM, RoseFigura JM, Sjölander K, Klinman JP (2012) Distribution and Properties of the Genes Encoding the Biosynthesis of the Bacterial Cofactor, Pyrroloquinoline Quinone. Biochem 51:2265-2275.

Sudek S, Haygood MG, Youssef DTA, Schmidt EW (2006) Structure of Trichamide, a Cyclic Peptide from the BloomForming Cyanobacterium Trichodesmium erythraeum, Predicted from the Genome Sequence. Appl Environ Microbiol 72:4382-4387.

Tamura K, Peterson D, Peterson N, Stecher G, Nei M, Kumar S (2011) MEGA5: Molecular Evolutionary Genetics Analysis Using Maximum Likelihood, Evolutionary Distance, and Maximum Parsimony Methods. Molecular Biology and Evolution.

Tamura K, Sakazaki R, Kosako Y, Yoshizaki E (1986) Leclercia adecarboxylata Gen. Nov., Comb. Nov., formerly known as Escherichia adecarboxylata. Current Microbiol 13:179184.

Tan Z-Y, Xu X-D, Wang E-T, Gao J-L, Martinez-Romero E, Chen W-X (1997) Phylogenetic and Genetic Relationships of Mesorhizobium tianshanense and Related Rhizobia. Int J Syst Bacteriol 47:874-879.

Tripura C, Sudhakar Reddy P, Reddy MK, Sashidhar B, Podile AR (2007) Glucose dehydrogenase of a rhizobacterial strain of Enterobacter asburiae involved in mineral phosphate solubilization shares properties and sequence homology with other members of enterobacteriaceae. Indian J Microbiol 47:126-131.

Yamada M, Sumi K, Matsushita K, Adachi O, Yamada Y (1993) Topological analysis of quinoprotein glucose dehydrogenase in Escherichia coli and its ubiquinone-binding site. J Biol Chem 268:12812-12817.

Zakria M, Ohsako A, Saeki Y, Yamamoto A, Akao S (2008) Colonization and growth promotion characteristics of Enterobacter sp. and Herbaspirillum sp. on Brassica oleracea (Soil Biology). Soil Sci Plant Nutr 54:507-516.

Zhang Y (2008) I-TASSER server for protein 3D structure prediction. BMC Bioinformatics 9:40

All the content of the journal, except where otherwise noted, is licensed under a Creative Commons License CC BY-NC. 